\title{
Blood lipid levels, thyroid status, and glucose tolerance in progressive partial lipodystrophy
}

\author{
B. M. RIFKIND AND J. A. BOYLE with the technical assistance of \\ MORNA GALE
}

\author{
From the 5th Floor Medical Unit and University Department of Medicine, \\ Royal Infirmary, Glasgow
}

SYNOPSIS Eight women with uncomplicated progressive partial lipodystrophy and two with progressive lipodystrophy and diabetes mellitus were studied. Plasma triglyceride levels were significantly elevated in the subjects with uncomplicated lipodystrophy; serum cholesterol, phospholipid, and plasma free fatty acid levels were normal. Paper electrophoresis showed increases in serum pre-beta lipoprotein and chylomicra. Thyroid function, as measured by radioiodine and stable iodine studies, was normal. Some subjects had a raised basal metabolic rate. Intravenous glucose tolerance was normal in patients with the uncomplicated disease.

Progressive partial lipodystrophy (Barraquer-Simons disease) is an uncommon condition characterized by the gradual disappearance of subcutaneous fat from the upper half of the body. Fat, in the lower half, remains unchanged or may increase in amount. In a disease in which a large proportion of the body's subcutaneous fat disappears, it might be expected that the blood lipids would be disturbed but there are few reports of lipid levels in progressive lipodystrophy.

Thyroid abnormalities, including thyrotoxicosis, and a mild diabetic state, are reputed to be found frequently in lipodystrophic subjects (Murray, 1952): however, we are unaware of any systematic studies of the thyroid function or glucose tolerance in patients with this condition.

We report here a study of blood lipid levels, thyroid status, and intravenous glucose tolerance in 10 patients with progressive partial lipodystrophy.

\section{MATERIAL AND METHODS}

Eight women with progressive partial lipodystrophy uncomplicated by overt diabetes or thyrotoxicosis were studied. Their ages ranged from 17 to 59 years (mean age 35 years). A further two female subjects, both aged 50 years, had progressive lipodystrophy, the development of which had antedated the onset of diabetes mellitus by many years. In all cases subcutaneous fat had begun to disappear in childhood or adolescence, and the distribution of the lipodystrophy conformed to the classical pattern. One patient had a nodular goitre

Received for publication 30 September 1966. but in other respects the subjects were apparently healthy.

The following studies were performed on some or all of the patients.

LIPID STUDIES The subjects fasted and abstained from smoking from the previous night, and were studied before they had risen in the morning or after resting for at least 20 minutes following their arrival at the hospital. Venous blood samples were obtained from them on one or more separate occasions and the following lipid levels were estimated on some or all of the blood samples: serum cholesterol by a ferric chloride technique using the Technicon AutoAnalyzer method N-24P; plasma triglyceride by the method of Van Handel and Zilversmit (1957); plasma phospholipid by the method of Bartlett (1959); and plasma free fatty acid by the method of Dole (1956) except that Nile blue-A was used as the indicator.

The lipoprotein fractions of sera from seven of the lipodystrophic subjects were examined by paper electrophoresis (Lees and Hatch, 1963).

When the level of a given lipid in a subject was estimated in more than one blood sample, the mean value of $N$ the results was taken. Lipid levels were also estimated in 17 apparently healthy female controls under similar conditions to those for the lipodystrophic patients (age range 17 to 40 , mean age 28 years).

THYROID STUDIES AND BASAL METABOLIC RATE Wayne, Koutras, and Alexander (1964) have shown that some $\Phi$ patients with simple goitre have abnormalities of stable $\stackrel{\mathscr{P}}{?}$ iodine metabolism. In view of the reported high incidence 0 of goitre in progressive partial lipodystrophy (Murray, $\vec{O}$ 1952) studies of stable iodine metabolism were therefore $\mathbb{D}$ undertaken in addition to the more usual tests of thyroid $\frac{O}{\mathbb{D}}$ function. The following tests were performed: thyroidal $\_$ radioiodine ${ }^{(131}$ ) uptake at 24 hours and plasma protein- $\frac{0}{2}$ 
bound ${ }^{131} \mathrm{I}$ at 48 hours following administration of a tracer dose $(25 \mu \mathrm{c})$ of ${ }^{131} I$ (Murray and McGirr, 1960); serum protein-bound stable iodine $\left(\mathbf{P B}^{127} \mathrm{I}\right)$ by the method of Farrell and Richmond (1961); plasma inorganic iodine level by the method of Boyle, Sloss, McDonald, and Gray (1965); and thyroidal plasma ${ }^{131}$ I clearance rate by the method of Berson, Yalow, Sorrentino, and Roswit (1952).

The absolute iodine uptake was calculated from a knowledge of the last two measurements (Boyle et al., 1965), basal metabolic rate (B.M.R.) was measured by spirometry on one or more occasions. The B.M.R. was calculated using the standards of Boothby and Sandiford (1929), normal values being within $\pm 15 \%$ of standard. The mean value of the repeated estimations on a given subject was taken.

INTRAVENOUS GLUCOSE TOLERANCE TESTS These were performed on the patients according to the method of Lundbaek (1962). The fall in blood sugar levels following the rapid intravenous injection of $25 \mathrm{~g}$. of glucose was plotted against time on semi-log paper and the $t \frac{1}{2}$ (time in minutes taken for blood glucose level to reach half its original value) was found from the straight line obtained by joining the points. The $\mathrm{k}$ value (diminution rate of blood sugar as per cent per minute) was obtained using the formula $\mathrm{k}=\frac{0.693}{\mathrm{t} \frac{1}{2}} \times 100$.

A $\mathrm{k}$ value above 1.05 is regarded as normal and below 0.95 as diabetic (Lundbaek, 1962).

\section{RESULTS}

LIPID STUDIES The mean values for the cholesterol, triglyceride, phospholipid, and free fatty acid levels of seven of the uncomplicated lipodystrophic subjects are shown in Table I, together with the corresponding results for the controls. No significant differences were found between cholesterol, phospholipid, or free fatty acid levels in the two groups of subjects. Plasma triglyceride levels were considerably and highly significantly elevated in the lipodystrophic subjects $(t=3.985 ; \mathrm{p}<0.001)$. Since
TABLE I

BLOOD LIPID LEVELS IN LIPODYSTROPHIC AND CONTROL SUBJECTS ${ }^{1}$

Cholesterol Triglyceride Phospholipid Free Fatty Acid Subjects (mg./100 ml.) (mg./100 ml.) (mg./100 ml.) ( $\mu \mathrm{Eq} . / \mathrm{l}$.

\begin{tabular}{lcccc}
\hline Lipodys- & $244 \pm 44$ & $132 \pm 42$ & $252 \pm 45$ & $547 \pm 300$ \\
trophy $\quad\left(7^{2}\right)$ & $(7)$ & $(6)$ & $(6)$ \\
Controls $231 \pm 55$ & $79 \pm 21$ & $242 \pm 47$ & $679 \pm 277$ \\
& $(15)$ & $(16)$ & $(16)$ & $(12)$
\end{tabular}

${ }^{1}$ Values refer to mean and standard deviation. ${ }^{2}$ Number of subjects studied.

plasma triglyceride levels have a lognormal distribution in the population (Carlson, 1960) the results were also calculated in the terms of the $\log _{10}$ triglyceride levels. A highly significant difference was again found $(t=3.667,0.001<\mathrm{p}<0.01)$. The mean triglyceride values for the two diabetic subjects were 104 and $273 \mathrm{mg}$. $/ 100 \mathrm{ml}$. respectively.

The paper electrophoretic analyses showed a prebeta lipoprotein band in all and a chylomicron band in some of the samples studied.

THYROID STUDIES AND BASAL METABOLIC RATE The results of the various thyroid studies are shown in Table II. The thyroidal 24-hour ${ }^{131}$ I uptake, serum P.B. ${ }^{131}$ I levels at 48 hours, and P.B. ${ }^{127}$ I levels were within normal limits. The plasma inorganic iodine levels were normal for all subjects studied apart from the one patient with the non-toxic nodular goitre whose level $(0.01 \mu \mathrm{g} . / 100 \mathrm{ml}$.) was in the iodine-deficient range (Boyle et al., 1965). This patient demonstrated a high thyroidal ${ }^{131}$ I clearance ( $59 \mathrm{ml} . / \mathrm{min} . / 1 \cdot 73 \mathrm{sq} . \mathrm{m}$.) such as has been described for non-toxic nodular goitre (Koutras, Alexander, Buchanan, Crooks, and Wayne, 1960); her absolute iodine uptake was within normal limits. The other patients had normal values with respect to these last two functions.

All subjects had normal blood urea levels, and in

TABLE II

RADIOIODINE AND STABLE IODINE STUDIES IN LIPODYSTROPHIC SUBJECTS

\begin{tabular}{|c|c|c|c|c|c|c|}
\hline Subject & $\begin{array}{l}\text { Thyroidal Plasma }{ }^{131} I \\
\text { Clearance Rate } \\
\left(\text { ml./min. } / 1 \cdot 73 \mathrm{~m}^{2}\right)\end{array}$ & $\begin{array}{l}\text { 24-Hour } \\
131 \text { I Uptake } \\
(\% \text { dose })\end{array}$ & $\begin{array}{l}\text { 48-Hour } \\
P B^{131} I \\
(\% \text { dose } / l . \text { plasma })\end{array}$ & $\begin{array}{l}\text { Plasma Inorganic } \\
\text { Iodine ( } \mu \mathrm{g} . \%)\end{array}$ & 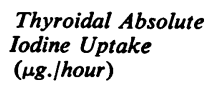 & $\begin{array}{l}P B^{127} I \\
(\mu g . / \%)\end{array}$ \\
\hline $\begin{array}{c}1 \\
2 \\
3 \\
4 \\
5 \\
6 \\
7^{1} \\
\text { Normal values }\end{array}$ & $\begin{array}{r}36 \\
32 \\
- \\
- \\
28 \\
34 \\
59 \\
44^{2} \\
(13-74)\end{array}$ & $\begin{array}{c}42 \\
32 \\
38 \\
-30 \\
41 \\
50 \\
20-55 \%\end{array}$ & $\begin{array}{c}\text { Negligible } \\
\text { Negligible } \\
\text { Negligible } \\
\text { Negligible } \\
\text { Negligible } \\
\text { Negligible } \\
<0.3 \%\end{array}$ & $\begin{array}{c}0.28 \\
0.18 \\
- \\
- \\
0.11 \\
0.12 \\
0.01 \\
0.24^{2} \\
(0.05-0.54)\end{array}$ & $\begin{array}{c}6 \cdot 0 \\
3 \cdot 4 \\
- \\
1 \cdot 8 \\
2 \cdot 4 \\
3 \cdot 5 \\
4 \cdot 7^{2} \\
(1 \cdot 1-14 \cdot 2)\end{array}$ & $\begin{array}{r}5 \cdot 7 \\
6 \cdot 4 \\
5 \cdot 5 \\
5 \cdot 6 \\
4 \cdot 8 \\
6 \cdot 2 \\
5 \cdot 1 \\
3 \cdot 5-7 \cdot 5\end{array}$ \\
\hline
\end{tabular}

${ }^{1}$ This patient had simple goitre.

${ }^{2}$ Values (mean and range) derived from 24 euthyroid female subjects. 
five, in whom the test was carried out, normal results were obtained for the renal clearance of ${ }^{127} \mathrm{I}$. It is therefore unlikely that renal dysfunction compromised the interpretation of the iodine studies.

The results of the B.M.R. estimations are shown in Table III. Two subjects had a raised B.M.R. and in another two it was at the upper limit of normal.

TABLE III

BASAL METABOLIC RATE (PERCENTAGE OF STANDARD) AND INTRAVENOUS GLUCOSE TOLERANCE (k VALUE) OF LIPODYSTROPHIC SUBJECTS

\begin{tabular}{lcc} 
Subject & $B . M . R$. & $k$ Value \\
\hline 1 & $+1(4)^{1}$ & $2 \cdot 89(1)$ \\
2 & $+14(4)$ & $1 \cdot 50(1)$ \\
3 & $+8(3)$ & $2 \cdot 31(1)$ \\
4 & $0(3)$ & $2 \cdot 57(1)$ \\
5 & $+14(1)$ & $3 \cdot 86(1)$ \\
$6^{2}$ & $+23(2)$ & -
\end{tabular}

${ }^{1}$ Number of estimations.

'Progressive partial lipodystrophy + mild diabetes mellitus.

INTRAVENOUS GLUCOSE TOLERANCE TEST These were performed on all subjects, excluding the two who had overt diabetes. The $k$ values (Table III) were all well within the limits of normality.

\section{DISCUSSION}

The results show that plasma triglyceride levels are elevated in subjects with progressive partial lipodystrophy. Levels of other blood lipids are unchanged. Senior and Gellis (1964), in their review, collected three examples of the occurrence of hyperlipaemia and reported a fourth. On the other hand Poley and Stickler (1963) found low or normal serum levels of cholesterol, total fatty acids, total lipids, and phospholipid. It is not known what relationship the diseases, sometimes known as congenital or acquired, generalized lipodystrophy bear to progressive partial lipodystrophy; they have several features which point to their being distinct syndromes. Hypertriglyceridaemia has also been found in both types of generalized lipodystrophy (Seip and Trygstad, 1963; Senior and Gellis, 1964) suggesting that the process of lipodystrophy per se, whatever the aetiology, is associated with hypertriglyceridaemia.

The presence of hypertriglyceridaemia, even in subjects in whom the lipodystrophic process appeared to have been arrested some time previously, suggests that the underlying biochemical disturbance may still operate even though it is prevented from further clinical expression due to depletion of affected sites.

The finding of pre-beta lipoprotein on paper electrophoresis demonstrates that at least some of the raised triglyceride levels of the subjects is of $\underline{\overrightarrow{0}}$ endogenous origin; a possible sequence of events $\stackrel{-}{\Rightarrow}$ leading to hypertriglyceridaemia might be an increased rate of lipolysis of subcutaneous fat due too some unknown cause, with a resulting increase in 흐 free fatty acid turnover and a rise in the rate of $\frac{\overline{\bar{p}}}{\overline{7}}$ hepatic triglyceride synthesis (Steinberg, 1963). The $\stackrel{\mathbb{Q}}{\square}$ normal plasma free fatty acid levels, which usually but not invariably reflect free fatty acid turnover (Steinberg, 1963; Armstrong, Steele, Altszuler,. Dunn, Bishop, and DeBodo, 1961), might be re- $\overrightarrow{\vec{\omega}}$ garded as evidence against an increased rate of ${ }^{\omega}$ lipolysis. However, without knowledge of the actual홍 amount of adipose tissue in these subjects it is difficult to draw conclusions about fatty acid mobili- . zation from adipose tissue from plasma free fatty $\overrightarrow{i n}$ acid levels. The chylomicron band found in some of the subjects on paper electrophoresis may be due to a delay in the clearance of dietary fat from $\vec{c}$ the plasma secondary to the increased amount of endogenously derived pre-beta lipoprotein (Nestel, $\stackrel{\vec{D}}{\frac{C}{2}}$ 1964).

In a review of 77 cases of lipodystrophy $21 \% \vec{\circ}$ were found to have some form of thyroid disorder (Murray, 1952) and it has been suggested that progressive partial lipodystrophy and thyrotoxicosis are related (Maranoñ and Soler, 1926). This led to the use of thyroidectomy in an attempt to benefit the condition, without success (Cohen and Eis, 1934).

Most of the cases of progressive partial lipodys- $\stackrel{\mathbb{Q}}{2}$ trophy previously reported occurred before radio- $\overrightarrow{\overrightarrow{0}}$ iodine and stable iodine methods were available for 3 studying thyroid function, and we are not aware of any cases in which the diagnosis of thyrotoxicosis was proven by such methods. We have been unable to demonstrate any consistent thyroid abnormality in these patients and, in particular, none of them was 3 found to be thyrotoxic. The high incidence of thyroid disorder previously reported might be partly explained by the tendency for thyrotoxic patients to develop an appearance which resembles lipodystrophy (Senior and Gellis, 1964). Murray (1952) has $\frac{D}{0}$ suggested that a hypermetabolic state exists in progressive lipodystrophy which is not due to thyroid $N$ overactivity, and there have been many reports of a $N$ raised B.M.R. in this condition and in generalized $N$ lipodystrophy. In two of our patients, both diabetic, $\omega$ the B.M.R. was raised and in two it was just below the upper level of normal $(+14 \%)$. However, we $\stackrel{0}{=}$ feel that more precise studies of metabolic rate are $\stackrel{\oplus}{\Phi}$ required before it can be accepted with confidence ? that hypermetabolism is a feature of this disease. These would require to take into account the re- $\overrightarrow{\mathbb{D}}$ duction in body fat, which may lead to fallaciously $\frac{?}{\mathbb{D}}$ high values for the B.M.R., by relating results to $\varrho$ lean body mass, although there is evidence that 
adipose tissue does participate in the body's utilization of oxygen (Keckwick, 1965). Disturbances in glucose tolerance also do not appear to be a primary feature of this disease as indicated by the normal findings for the intravenous glucose tolerance tests in the subjects with the uncomplicated disease.

We wish to thank Dr. A. Brown for advice with the manuscript. We are grateful to Professor E. M. McGirr, Dr. E. G. Oastler, Mr. J. Tough, and Mr. A. McNeil for permission to study their patients. We are indebted to Imperial Chemical Industries Ltd., for financial support.

\section{REFERENCES}

Armstrong, D. T., Steele, R., Altszuler, N., Dunn, A., Bishop, J. S. and De Bodo, R. C. (1961). Amer.J. Physiol., 201,9.

Bartlett, G. R. (1959). J. Biol. Chem., 234, 449.

Berson, S. A., Yalow, R. S. Sorrentino, J., and Roswit, B. (1952). J. clin. Invest., 31, 141.
Boothby, W. N., and Sandiford, I. (1929). Amer. J. Physiol., 90, 290. Boyle, J. A., Sloss, A., MacDonald, E., and Gray, M. (1965). J. clin. Endocr., 25, 1035.

Carlson, L. A. (1960). Acta med. Scand., 167, 377.

Cohen, S. J., and Eis, B. M. (1934) Arch. Neurol. Psychiat. (Chic.), $32,184$.

Dole, V. P. (1956) J. clin. Invest., 35, 150.

Farrell, L. P., and Richmond, M. H., (1961) Clin. chim. Acta, 6, 620.

Keckwick, A. (1965) Adiposity. Adipose Tissue. Williams and Wilkins, Baltimore.

Koutras, D. A., Alexander, W. D., Buchanan, W. W., Crooks, J., and Wayne, E. J. (1960) Lancet, 2, 784.

Lees, R. S., and Hatch, F. T. (1963) J. Lab. clin. Med., 61, 518.

Lundbaek, K. (1962) Brit. med. J., 1, 1507.

Maranoñ, G., and Soler, J. B. (1926). Endocrinology, 10, 1.

Murray, I. (1952) Brit. med. J., 2, 1236.

Murray, I. P. C., and McGirr, E. M. (1960) Brit. med.J., 1, 838.

Nestel, P. J. (1964) J. clin. Invest., 43, 943.

Poley, J. R., and Stickler, G. B. (1963) Amer. J. Dis. Child., 106, 356.

Seip, M., and Trygstad, O. (1963) Arch. Dis. Child., 38, 447.

Senior, B., and Gellis, S. S. (1964). Pediatrics, 33, 593.

Steinberg, D. (1963) Biochem. Soc. Symp., 24, 111.

Van Handel, E., Zilversmit, D. B. (1957) J. Lab. clin. Med., 50, 152.

Wayne, E. J., Koutras, D. A., and Alexander, W. D. (1964). Clinical Aspects of Iodine Metabolisms. Blackwell, Oxford. 